\title{
An Analysis of the Opportunities and Challenges of Internet Finance in the New Normal of Economy
}

\author{
Hunyuan Gao*
}

Sichuan University, Chengdu City 610065, Sichuan Province, China. E-mail: wqtr45@qq.com

\begin{abstract}
The vigorous development of Internet finance is very important for the sustainable development of China's economy. In recent years, Chinese government has vigorously supported the development of enterprises, and issued a series of policies related to finance, tax and financing guarantee support. For enterprises, this is not sufficient. In addition to the support of external policies, enterprises need more self-examination. The financial management system of many enterprises is not perfect and the quality of financial management is low, which will have a negative impact on the operation and management of enterprises and can not effectively guarantee the quality of financial information of enterprises.
\end{abstract}

Keywords: New Normal of Economy; Online Finance; Analysis; Challenges

\section{Internal financial management objectives of enterprises under the new normal of economy}

The internal financial management of an enterprise is implemented by the board of directors, management and all employees of each enterprise. Its main purpose is to effectively ensure a series of management and control activities to achieve the basic objectives of the enterprise. The financial management of enterprises mainly has the following five objectives: (1) to achieve various strategies of enterprises; (2) to ensure the efficiency of operation; (3) to ensure the authenticity and effectiveness of financial reports and management processes and other information; (4) to ensure the relative safety and integrity of assets; (5) to comply with the relevant provisions of the state. These five goals are to ensure and achieve the business management objectives of the enterprise. In 2002, famous American economic action Sarbanes Oxley stipulated that American companies are required to disclose financial management reports on enterprises. In addition, the following provisions are made on the specific content and form of the financial management report of the enterprise: (1) the statement management authority shall be responsible for the establishment and maintenance of sufficient internal risk control structure and financial management procedures of the financial report of the listed company; (2) it must be responsible for the internal control of the financial report of the listed company that issues bonds at the end of the latest year whether the structure and financial management procedures are specific and effective.

\footnotetext{
Copyright (C) 2020 Hunyuan Gao

doi: $10.18282 /$ ff.v9i2.867

This is an open-access article distributed under the terms of the Creative Commons Attribution Non-Commercial License

(http://creativecommons.org/licenses/by-nc/4.0/), which permits unrestricted non-commercial use, distribution, and reproduction in any medium, provided the original work is properly cited.
} 


\section{Main influencing factors}

\subsection{Internal environmental impact of the enterprise}

The internal environment is the basic element of financial management, which mainly includes organizational structure, power and responsibility distribution, corporate culture, governance structure, and anti fraud mechanism. From the perspective of corporate culture, many managers do not attach great importance to financial management. They think that financial management is unnecessary. Over time, their attitude and behavior towards financial management will gradually affect employees to gradually fail to comply with the relevant provision of the company's financial management. The deeper reason is that the understanding of financial management is biased. They think that the improvement of financial management is a constraint on themselves, and only see the immediate interests, regardless of the long-term interests of the enterprise's future development ${ }^{[1]}$. From the perspective of power and responsibility distribution and fraud mechanism, the boss of an enterprise determines most of the economic activities of the enterprise; as the enterprise is too small to have enough funds to hire too many financial personnel, the accounting and financial responsibilities are mixed together, or one person undertakes these tasks. At the same time, most business owners are not clear about financial information, which is prone to accounting fraud and financial fraud. The internal environment of these kinds of enterprises makes the quality of financial management low, which is harmful to the quality of financial information.

\subsection{Impact of risk assessment}

Risk assessment is also an important aspect that affects the quality of financial information. Regardless of the size and form of enterprises, enterprises should do a basic risk assessment. Enterprise risk can be divided into controllable risk and uncontrollable risk. In the enterprise management, due to the imperfect market economic system in China, few people realize the importance of risk. With the advent of the information age, enterprise management is also developing. If an enterprise cannot effectively discover the risks it is facing or may face in the future during its operation, they can not deal with them quickly, which may hit the production and operation of enterprises. Some enterprises will disguise their mismanagement, whitewash their mistakes and make financial fraud, which will affect the authenticity of financial information. On the other hand, the financial personnel of some enterprises are the elderly, who are not a good at using computers to keep accounts or not proficient in using computers and financial software. They are prone to make mistakes in the operation process which are difficult to be found. It also affects the authenticity of financial information. If enterprises do not pay attention to risking assessment, the quality of financial information will be damaged by the risks.

\subsection{Impact of the control activities}

Enterprise control activities need the enterprise to make the business objectives correctly. In the process of realizing the business objectives of the enterprise, the instructions issued or the effective measures taken, and effective control of activities can help enterprise leaders and management to make further decisions and better manage employees. And active and effective control activities for the production, operation and finance of enterprises, to a certain extent, can help enterprises to achieve the purpose of risk aversion, effectively avoid the low quality of financial information caused by internal risks. Therefore, carrying out effective financial management activities will help to improve the quality of financial information and promote the long-term development of enterprises.

\subsection{Impact of information and communication}

For enterprises, how to receive internal and external information quickly, and whether it is accurate is very important. Scientific and accurate collection of economic information and its effective analysis and processing will have a direct influence on the quality of financial information of enterprises. It is one of the essential ways to realize the efficient transmission of external and internal information, superior and subordinate information of enterprises. If the 
internal communication of the enterprise is not proper and enough, it is easy for the superior and subordinate to transmit information with deviation, especially the financial information. Once the financial information has deviation, the quality of the financial information of the enterprise cannot be guaranteed. Therefore, enterprises should take the improvement of information communication ability as an important part of management, and try to improve the information communication ability of financial personnel.

\subsection{Impact of internal supervision}

External supervision and internal supervision are two ways to supervise the quality of financial information. Internal supervision is an important aspect and a basic element of enterprise financial management, whose essence is to check the economic activities of enterprises, find out the existing problems in time and solve them efficiently. Monitoring the financial work of enterprises can make financial information more standardized and accurate, and to a certain extent, prevent the dishonesty of financial information ${ }^{[2]}$.

\section{Development strategy}

\subsection{Improve the internal environment of the enterprise}

The internal environment of an enterprise is the basis of financial management. The urgent task is to improve the internal environment of an enterprise. To improve the internal environment, it should start from the corporate culture and the distribution of power and responsibility. From the aspect of corporate culture, it is necessary to strengthen the internal study and publicity of financial management ideas, and improve the ideological awareness of employees in this aspect. To implement this measure, the first thing is to change the leaders' wrong understanding of financial management, so that they can understand the significance of financial management of enterprises, which is to ensure the safety and integrity of economic resources of enterprises, ensure the correctness and reliability of economic information and financial information, balance economic behavior, and promote the healthy development of enterprises. This is an important step to improve the quality of enterprise financial management. Then, the enterprise should organize the training for the employees, so that they can fully understand the financial management ideas, understand the financial management system of the enterprise, and make it clear that everyone has the responsibility to strengthen the financial management. From the aspect of power and responsibility distribution, it is necessary to reasonably allocate the relevant responsibilities of each position, which is mutually restricted. Mixing responsibilities to one position will cause too much pressure on employees and is prone to financial fraud, accounting fraud and other issues, which is not conducive to improving the quality of financial information.

\subsection{Improve enterprise risk assessments}

To improve the anti risk ability of enterprises, the most direct way is to reduce liabilities and improve the cash flow ratio. Enterprises has more cash flow and strong anti risk ability. But for business, there may not be a lot of cash flow. It is urgent to improve the anti risk ability, the quality of financial information and the risk assessment of enterprises. In order to improve the risk assessment ability of an enterprise, the management of the enterprise must first define the risk itself, including the possibility, duration, main areas and key risk points of the risk. Then the judgment that the enterprise needs to make is whether the impact of risk on the enterprise is direct or indirect, and whether it will cause a series of chain reactions and other risks. Finally, enterprises should define the consequences of the risk, and judge whether it will cause loss to the enterprise, whether the loss can be avoided, and the cost that the enterprise needs to pay, etc. Some enterprises may find that the loss brought by risks is less than the loss of risk aversion after making a prediction, and then they often choose to let the risk happen. In the short term, it seems that enterprises don't lose too much money, but in the long term, risks may gradually increase the loopholes in production and operation, financial information and other aspects of enterprises, affect the quality of financial information, and affect the healthy development of enterprises. 


\subsection{Ensure effective financial management activities}

The financial management activities of enterprises mainly include responsibility division control, authorization control, review and approval control, budget control, property protection control, financial system control, performance evaluation control, and information technology control. In addition to a series of countermeasures for enterprise risks, scientific and reasonable financial management activities of enterprises also need to be reflected in the daily economic business of enterprises. (1) In the process of enterprise management, the safety of property and the effective use of resources should always be guaranteed. Enterprises needs to sort out the smooth asset management, find the weak points in asset management and improve them. Employees of the enterprise shall abide by the county magistrate's asset management system and manage all assets according to strict procedures. Enterprises needs to ensure the reasonable allocation of resources, especially for enterprises whose cost accounts for the majority of enterprise expenditure. The raw materials of the enterprise should be taken reasonably to avoid the loss and waste, and these withdrawals should be recorded in a timely manner to ensure the timely and accurate information and the quality of financial information. (2) Staff responsibilities and the rules and regulations should be clear. For example, the person in charge of purchasing should not be responsible for acceptance, or the merchandiser of the enterprise can not be responsible for collection. The former cannot guarantee the quality of the purchased products, and the latter cannot guarantee that the merchandiser will collect the difference. The assets of an enterprise should also be placed reasonably, for example, the assets that have been inspected and accepted are easily mixed up with those that have not been inspected and accepted if there is any carelessness ${ }^{[3]}$. In the process of asset acceptance, the acceptance personnel shall also record in time to prevent forgetting or remembering mistakes later.

\subsection{Promote enterprise information and communication}

In work communication, it is extremely important to be concise and comprehensive. Reporting and communicating should be short and direct. In terms of parallel communication, pay attention to the following points: aligning on the fact, agreeing on the outcome, assuming nothing, setting priorities and clarifying responsibilities. In terms of top-down communication, enterprise managers and leaders should also make clear what they want to express or the instructions they try to convey.

\subsection{Strengthen internal supervisions of enterprises}

Internal supervision of enterprises involves all aspects of enterprises. In order to improve the supervision mechanism of enterprises, the following aspects must be achieved. (1) Strengthen the supervision consciousness of all levels of the enterprise. Employees should try their best to understand the business activities of the enterprise and cultivate the awareness of supervision, while the management and leadership of the enterprise should possess the awareness of consciously accepting supervision. (2) Improve the supervision mechanism of enterprises and strengthen the effective supervision of corporate finance. In order to ensure the effective operation of financial information within the enterprise, it is necessary to conduct effective supervision of financial activities. Accounting or financial personnel should accurately record the source and expenditure of each financial information, and cooperate with corporate supervision. The financial risks and financial fraud found in the process of supervision also need to be effectively solved. (3) Innovate the way of internal supervision so that employees can supervise through more channels. Enterprises can take anonymous reporting measures to supervise the management, so as to avoid employees' thoughts of not being able to supervise or report.

\section{Conclusion}

With the increasingly frequent economic exchanges in the world, the continuous progress of society and the acceleration of China's reform and opening up, there are more and more aspects and angles of integration between China and the world. The world is changing rapidly, and the economy is getting closer, deepening and integrating with each other. With these changes, the organizational form and business activities of enterprises begin to show more and 
more complex structure and form, and achieve great results. The financial management ability of an enterprise is the most important factor in its development and the basic premise for its normal operation. Relying solely on external resources to make up for their individual debts can not only solve the problem of lack of funds, but also make finance more efficient to play a greater advantage and bring more economic benefits to the society.

\section{References}

1. Zhang J. Problems and countermeasures of financial accounting management in the era of network economy (in Chinese). Chinese and Foreign Entrepreneurs 2016; (4): 172.

2. Zhou W. Innovative ideas and countermeasures of enterprise financial management in the context of network economy (in Chinese). Jiangsu Business Theory 2018; (6): 177.

3. Lin X. Improvement measures of financial accounting management in the era of network economy. Business Manager 2016; (18): 164. 